\title{
Are birth outcomes in low risk birth cohorts related to hospital birth volumes? A systematic review
}

Felix Walther ${ }^{1,2^{*}}$, Denise Kuester ${ }^{1}$, Anja Bieber ${ }^{3}$, Jürgen Malzahn ${ }^{4}$, Mario Rüdiger ${ }^{5,6+}$ and Jochen Schmitt ${ }^{1,6+}$

\begin{abstract}
Background: There is convincing evidence that birth in hospitals with high birth volumes increases the chance of healthy survival in high-risk infants. However, it is unclear whether this is true also for low risk infants. The aim of this systematic review was to analyze effects of hospital's birth volume on mortality, mode of delivery, readmissions, complications and subsequent developmental delays in all births or predefined low risk birth cohorts. The search strategy included EMBASE and Medline supplemented by citing and cited literature of included studies and expert panel highlighting additional literature, published between January/2000 and February/2020. We included studies which were published in English or German language reporting effects of birth volumes on mortality in term or all births in countries with neonatal mortality $<5 / 1000$. We undertook a double-independent title-abstract- and full-text screening and extraction of study characteristics, critical appraisal and outcomes in a qualitative evidence synthesis.

Results: 13 retrospective studies with mostly acceptable quality were included. Heterogeneous volume-thresholds, risk adjustments, outcomes and populations hindered a meta-analysis. Qualitatively, four of six studies reported significantly higher perinatal mortality in lower birth volume hospitals. Volume-outcome effects on neonatal mortality $(n=7)$, stillbirths $(n=3)$, maternal mortality $(n=1)$, caesarean sections $(n=2)$, maternal $(n=1)$ and neonatal complications $(n=1)$ were inconclusive.

Conclusion: Analyzed studies indicate higher rates of perinatal mortality for low risk birth in hospitals with low birth volumes. Due to heterogeneity of studies, data synthesis was complicated and a meta-analysis was not possible. Therefore international core outcome sets should be defined and implemented in perinatal registries.
\end{abstract}

Systematic review registration: PROSPERO: CRD42018095289

Keywords: Mortality, Infant, Low risk birth, Perinatal regionalization, Volume-outcome

\section{Background}

Several studies have shown mortality of high-riskinfants can be reduced if these infants are treated in highly equipped neonatal intensive or intermediate care units [1]. Therefore, different levels of care have been

*Correspondence: Felix.walther@uniklinikum-dresden.de

${ }^{\dagger}$ Mario Rüdiger and Jochen Schmitt contributed equally to this work.

${ }^{1}$ Center for Evidence-Based Healthcare, Medical Faculty Carl Gustav

Carus, TU Dresden, Fetscherstraße 74, 01307 Dresden, Germany

Full list of author information is available at the end of the article introduced for treatment of pregnant women and their newborns in relation to the medical condition. For each level certain requirements in terms of infrastructure, staffing, equipment and qualifications are defined. If a centre does not fulfill these requirements, a specialized care is usually not allowed [2,3]. Since experience of the care team is likely to be also of advantage, it could be assumed that infants will benefit from hospitals with high annual birth volume. That assumption is supported by our recent systematic review, showing for very low birth

(c) The Author(s) 2021, corrected publication 2021. Open Access This article is licensed under a Creative Commons Attribution 4.0 International License, which permits use, sharing, adaptation, distribution and reproduction in any medium or format, as long as you give appropriate credit to the original author(s) and the source, provide a link to the Creative Commons licence, and indicate if changes were made. The images or other third party material in this article are included in the article's Creative Commons licence, unless indicated otherwise in a credit line to the material. If material is not included in the article's Creative Commons licence and your intended use is not permitted by statutory regulation or exceeds the permitted use, you will need to obtain permission directly from the copyright holder. To view a copy of this licence, visit http://creativecommons.org/licenses/by/4.0/. The Creative Commons Public Domain Dedication waiver (http://creativecommons.org/publicdomain/zero/1.0/) applies to the data made available in this article, unless otherwise stated in a credit line to the data. 
weight infants an improved maternal and neonatal outcome in centers with higher birth volumes in high-risk births [4].

Important other risk factors for pregnancy and birth complications are higher maternal age, comorbidities (e.g. placenta praevia, pre-existing or gestational diabetes) or smoking. These factors are likely to increase the risks for maternal or neonatal adverse events [5-10]. Currently, appropriate management of these risks is still being discussed [11-15]. In order to better study the impact of different interventionson on subsequent outcome, a homogenous definition of birth outcomes is needed and core outcome sets (COS) are currently developed $[5,6]$. COS are multilaterally consented and standardized sets of outcomes which should be reported in clinical trials to guarantee comparabilityIn recent years, COS have been increasingly developed and registered for perinatal and maternal care [16], like gestational diabetes [17], preterm birth [18], maternity care [19], neonatal medicine [20] or pregnancy and childbirth [21]. However, currently there are no COS available to study the impact of birth volume on outcome of low risk pregnancies. For both this reason and since birth complications are difficult to predict in low risk pregnancies, it remains unknown whether women with a low risk pregnancy could also benefit from care in hospitals with higher birth volumes.

The aim of this systematic review was to summarize and critically appraise the impact of hospital case volume on mortality and morbidity in low risk birth cohorts.

\section{Methods}

We conducted this systematic review in accordance with the Preferred Reporting Items for Systematic Reviews and Meta-Analyses (PRISMA) Checklist [22] and registered the review protocol (CRD42018095289) in the International Prospective Register of Systematic Reviews [23]. The original search strategy (Additional file 1) and review was designed to identify studies on the effects of either perinatal regionalization or hospital birth volume on infant and maternal outcomes. Here we report on the results of volume-outcome-relationships.

\section{Eligibility criteria, information sources, search strategy} Inclusion and exclusion criteria (Table 1) addressed population, intervention, comparison, outcome and study type (PICOS). Interventions/ expositions included volume effect estimates on mortality as primary outcome and secondarily on caesarean sections, readmissions, birth complications, developmental delays (outcome) in all births or a pre-defined low risk birth cohort (population). In order to ensure comparability and current status of obstetric care, observational or interventional studies (study type) from countries with neonatal mortality rates below 5 per 1000 births (UN Child mortality report) that were published in English or German language after 01/01/2000 were included [24].

\section{Study selection}

We systematically searched Medline and EMBASE on $18 / 04 / 2018$ and on $26 / 02 / 2020$. The search strategy included a combination of free text words and database-specific subject-headings (Additional file 1) using Ovid interface. We used Endnote X7 for the creation of the literature database and the removal of duplicates. Two authors (FW, $\mathrm{AB}$ ) independently screened titles/ abstracts and full texts for eligibility. Additionally, an expert panel (MR, JM, Rainer Rossi) highlighted missing relevant papers. After full-text-screening, we conducted a hand search including forward (citing literature) and backward (cited literature) screening of included studies. Discrepancies during screening, extraction or quality assessment were solved by consulting of another reviewer (JS). For interpretation of reliability, we applied the prevalence-adjusted bias-adjusted kappa (PABAK). The advantage of PABAK in contrast to Kappa value is the consideration of the high class imbalance [25].

Table 1 PICO-Scheme

\begin{tabular}{|c|c|c|}
\hline & Inclusion criteria & Exclusion criteria \\
\hline POPULATION & $\begin{array}{l}\text { all births, term/ normal birth weight birth or low risk birth in a } \\
\text { nationwide setting with }<5 / 1000 \text { neonatal deaths }\end{array}$ & $\begin{array}{l}\text { Preterm birth, low birth weight birth, other risk-selections } \\
\text { (e.g. gestational diabetes, multiple births) }\end{array}$ \\
\hline EXPOSITION & comparison of different hospital birth volumes or -sizes & No comparison of different hospital birth volumes or -sizes \\
\hline COMPARISON & other birth volumes & No comparator provided \\
\hline OUTCOME & $\begin{array}{l}\text { Primary Outcome: Maternal or infant mortality } \\
\text { Secondary Outcomes: Caesarean sections, readmissions, birth } \\
\text { complications, developmental delays }\end{array}$ & No measurement of maternal or infant mortality \\
\hline STUDYTYPE & Observational and interventional studies & Descriptive studies, systematic reviews \\
\hline
\end{tabular}




\section{Data extraction and data synthesis}

We predefined a data extraction form in MS Excel including study charateristics (e.g. population, period, country) and outcomes (e.g. definition, exposing/ referencing annual volume, result, estimator) was used. One reviewer extracted (FW) and a second (DK) verified the results resolving discrepancies by consensus or consulting a third reviewer (JS). To decide whether individual studies can be pooled in a meta-analysis, we reviewed methodological quality, comparability of the study contexts (population, outcomes, volume-thresholds and risk adjustment) and statistical heterogeneity. If studies were considered as not comparable, a qualitative synthesis followed.

\section{Critical appraisal process}

Two independent reviewers (FW, DK) performed the quality assessment using the Methodology Checklist for Cohort studies of the Scottish Intercollegiate Guidelines Network (SIGN). This checklist contains 14 items with a final quality rating of the studies in "high quality", "acceptable" and "inacceptable" [26]. Methodological explanations and definitions in the context of the application of the checklist are presented in Additional file 2 .

\section{Patient and public involvement}

No patient involved.

\section{Results}

Study selection

After screening of 7955 records 13 studies met our predefinded eligibility criteria were included in the systematic review (Fig. 1) [27-39]. Additional file 3 contains the reasons for exclusion of the remaining 30 full texts [40-69]. The high prevalence and bias adjusted Kappa (PABAK) (Fig. 1) in both title-abstract and full-text-screnning suggests no systematic differences between the raters.

\section{Study characteristics}

Table 2 shows the characteristics of included studies. The observation period varied between 29 years (19671996) [33] and one year [35, 39]. The earliest observation started in 1967 [33] and the latest ended 2012 [39]. All of the included studies used cross-sectional designs to analyse retrospective cohorts in perinatal registers (Additional file 4). The studies were conducted in Finland [30, 32, 34], the United States [28, 35, 39], Sweden [27], Norway [33], Germany, [29] the United Kingdom, [31] Australia, [36] the Netherlands [70] and Canada [37]. The analyzed populations consist of either all births [27, $28,30,31,33-35,37,39$ ] and/ or a predefined low risk

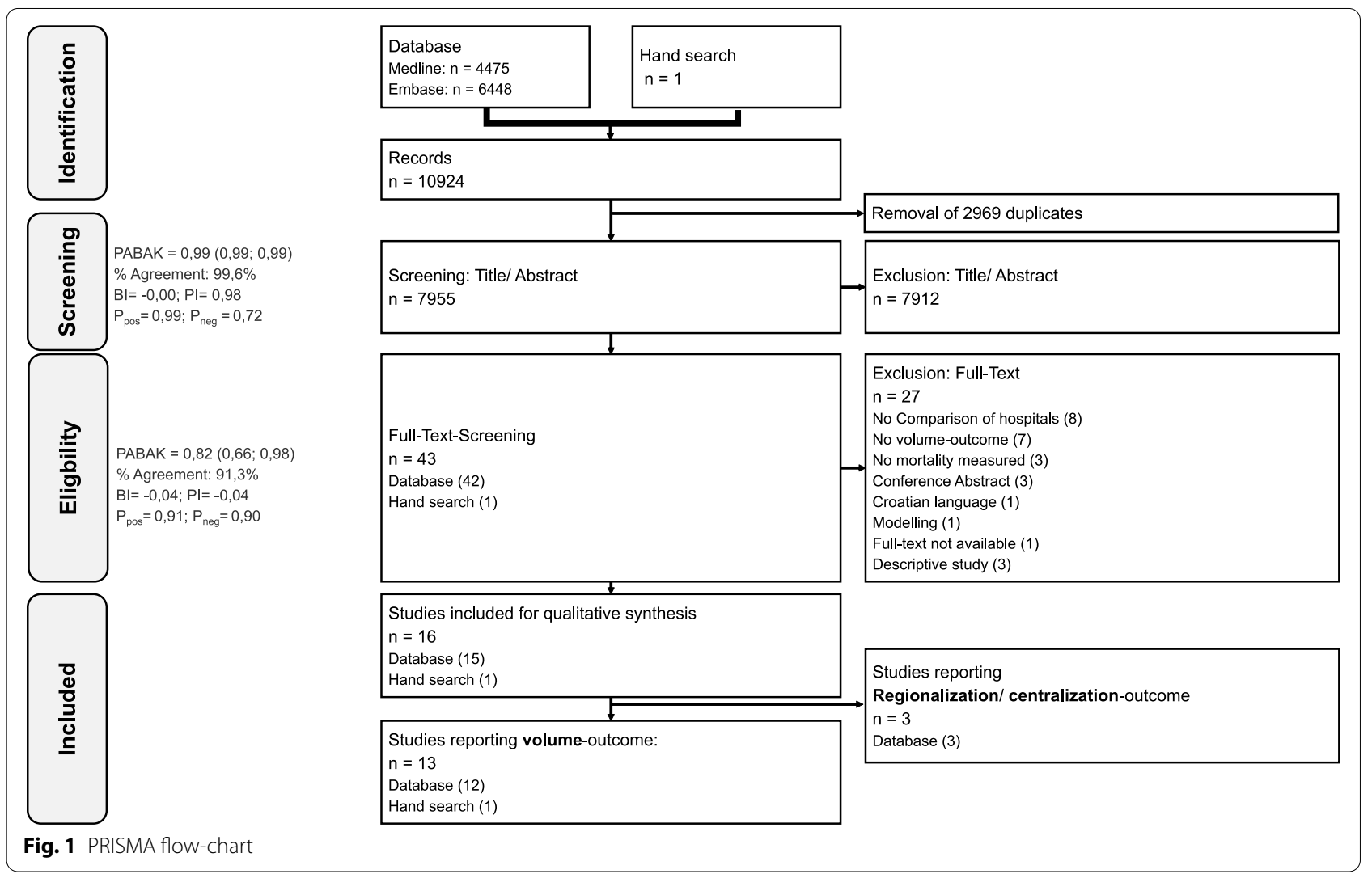


Table 2 Characteristics of included studies

\begin{tabular}{|c|c|c|c|c|c|c|}
\hline Study & Period & Country & Birth population & $\begin{array}{l}\text { Grouped annual } \\
\text { hospital volume }\end{array}$ & Outcomes & Outcome definition \\
\hline Finnstrom et al. 2006[27] & 1985-1999 & SWE & births: all singletons ( $\mathrm{n}=1.538 .814$ ) & $\begin{array}{l}<500,500-999,1000- \\
2499 \text { (ref.), } \geq 2500\end{array}$ & 1) neonatal mortality & 1) $\leq 27 d$ \\
\hline Friedman et al. 2016[28] & $1998-2010$ & US & $\begin{array}{l}\text { women: all hospital } \\
\qquad(\mathrm{n}=50.433 .539)\end{array}$ & 50,1000 (ref.), 1500,2250 & $\begin{array}{l}\text { 1) maternal mortality } \\
\text { 2) maternal complica- } \\
\text { tions }\end{array}$ & $\begin{array}{l}\text { 1) failure to rescue } \\
\text { 2) severe morbidity }\end{array}$ \\
\hline Heller et al. 2002[29] & 1990-1999 & GER & births: $B W>2500 \mathrm{~g}(\mathrm{n}=582.655)$ & $\begin{array}{l}\leq 500,501-1000 \\
\quad 1001-1500,>1500 \\
\quad \text { (ref.) }\end{array}$ & 1) Early-neonatal death & 1) $\leq 7 d$ \\
\hline Hemminki et al. 2011[30] & $1991-2008$ & FIN & $\begin{array}{l}\text { births: all } \\
(\mathrm{n}=474.419)+\mathrm{BW}>2499 \mathrm{~g} \text { in } \\
\text { non-UH }\end{array}$ & $\begin{array}{l}<750,750-1499, \geq 1500 \\
\text { UH (ref.) }\end{array}$ & $\begin{array}{l}\text { 1) perinatal mortality } \\
\text { 2) CS }\end{array}$ & 1) $\leq 7 d$ \\
\hline Joyce et al. 2004[31] & 1994-1996 & UK & births: all $(n=540.834)$ & $\begin{array}{l}\text { N/A: Volume entered the } \\
\text { analysis as continuous } \\
\text { variable }\end{array}$ & $\begin{array}{l}\text { 1) stand. stillbirth rates } \\
\text { 2) stand. neonatal } \\
\text { mortality }\end{array}$ & $\begin{array}{l}\text { 1) }>24 w k G A \\
\text { 2) } \leq 28 d\end{array}$ \\
\hline Karalis et al. 2016[32] & $2005-2009$ & $\mathrm{FIN}$ & births: low risk ${ }^{2}(n=276.066)$ & $\begin{array}{l}\text { births: } \leq 999,1000- \\
1999, \geq 2000, \text { UH (ref.) }\end{array}$ & $\begin{array}{l}\text { 1) stillbirths } \\
\text { 2) early neonatal death }\end{array}$ & $\begin{array}{l}\text { 1) Intrapartum: unde- } \\
\text { fined } \\
\text { 2) undefined }\end{array}$ \\
\hline Moster et al. 2001[33] & 1967-1996 & NO & births: all $(n=1.650 .852)$ & $\begin{array}{l}\leq 100,101-500 \\
501-1000,1001-2000 \\
2001-3000,>3000 \\
\text { (ref.) }\end{array}$ & 1) neonatal mortality & 1) $\leq 28 d$ \\
\hline Pyykonen et al. 2014[34] & $2006-2010$ & FIN & $\begin{array}{l}\text { women: } \text { all }^{3}(n=290.288)+\text { low } \\
\text { risk }^{4}(n=276.287)\end{array}$ & $\begin{array}{l}<1000,1000-2999 \\
\quad(\text { ref.) },<3000\end{array}$ & $\begin{array}{l}\text { 1) perinatal mortality } \\
\text { 2) neonatal mortality } \\
\text { 3) early neonatal } \\
\text { mortality } \\
\text { 4) stillbirths }\end{array}$ & $\begin{array}{l}\text { 1) stillbirth + death } \leq 7 d \\
\text { 2) } \leq 28 d \\
\text { 3) } \leq 7 d \\
\text { 4) } \geq 22 \mathrm{wk} \mathrm{GA}\end{array}$ \\
\hline Snowden et al. 2012[35] & 2006 & US & women: all $(n=527.617)$, low risk ${ }^{5}$ & $\begin{array}{l}\text { Urban: } \leq 50-1199 \\
\text { (ref.), } 1200-2399 \\
\text { 2400-3599; } \geq 3600 \\
\text { Rural: } 50-599 \text { (ref.) } \\
600-1699 ; \geq 1700\end{array}$ & 1) neonatal mortality & 1) undefined \\
\hline Tracy et al. 2006[36] & 1999-2001 & AUS & births: low risk/ term ${ }^{6}(\mathrm{n}=331.147)$ & $\begin{array}{l}<100,100-500 \\
501-1000,1001- \\
2000,>2001 \text { (ref.) }\end{array}$ & $\begin{array}{l}\text { 1) neonatal mortality } \\
\text { 2) CS (labour) } \\
\text { 3) Overall CS }\end{array}$ & 1) $\leq 28 d$ \\
\hline de Graaf et al. 2010[38] & $2000-2006$ & NEL & women: singleton $(n=655.961)$ & $\begin{array}{l}<750,750-999,1000- \\
1249,1250-1499 \\
1500-1749, \geq 1750 \\
\text { (ref.) }\end{array}$ & $\begin{array}{l}\text { 1) perinatal mortality } \\
\text { 2) neonatal complica- } \\
\text { tions }\end{array}$ & $\begin{array}{l}\text { 1) } \leq 7 d \\
\text { 2) Perinatal adverse } \\
\text { outcome }^{7}\end{array}$ \\
\hline Restrepo et al. 2018[39] & 2012 & US & $\begin{array}{l}\text { births: live } 20-44 \text { wk GA } \\
\qquad(\mathrm{n}=32.140)\end{array}$ & $\begin{array}{l}\text { N/A: Volume entered the } \\
\text { analysis as continu- } \\
\text { ous variable }\end{array}$ & 1) neonatal mortality & 1) $\leq 28 d$ \\
\hline $\begin{array}{l}\text { Aubrey-Brassler et al. } \\
2019[37]\end{array}$ & $2006-2009$ & CA & $\begin{array}{l}\text { women: all }(n=820.761) / \\
\text { births: all }(n=827.504)\end{array}$ & $\begin{array}{l}\text { No services usually; } \\
\text { 1-49; 50-99; 100-199; } \\
\text { 200-499; 500-999; } \\
\text { 1000-2499, > 2500 } \\
\text { (ref.) }\end{array}$ & $\begin{array}{l}\text { 1) perinatal mortality } \\
\text { 2) maternal complica- } \\
\text { tions }\end{array}$ & $\begin{array}{l}\text { 1) Death }[\ldots]^{8} \\
\text { 2) Maternal Morbidity \& } \\
\text { Mortality }^{9}\end{array}$ \\
\hline
\end{tabular}

\section{Notes:}

1: heart/ renal/ respiratory failure, acute myocardial infarction, liver disease, disseminated intravascular coagulation, coma, delirium, puerperal cerebrovascular disorders, pulmonary edema or embolism, sepsis, shock, status asthmaticus, status epilepticus

2; Exclusion: Low BW, multiple pregnancy, antepartum stillbirth, out-of-hospital birth, major congenital anomalies, birth defects

3: Exclusion: birth in university hospital, length of stay $>7 \mathrm{~d}$

4: Exclusion: birth in university hospital, length of stay $>7 \mathrm{~d}$, multiple pregnancy, pre-/postterm birth

5: Exclusion: preterm birth, low BW

6: Exclusion: Low BW, multiple pregnancy, preterm, age, complications

7: intrapartum death, death $\leq 7 \mathrm{~d}, 5$-min Apgar $<7$, NICU transfer

8: sudden infant death syndrome, sudden cardiac death, stillbirth ( $\mathrm{GA} \leq 20 \mathrm{wk}$ ), in-hospital death liveborn neonate

9: Eclampsia, Previa with hemorrhage abruption, Intrapartum + postpartum hemorrhage + transfusion or hysterectomy, Rupture of uterus before or during labor, Obstetric shock, Sepsis, Other complications of obstetric procedures, Obstetric embolism, Cardiovascular disease, Acute renal failure, Death, obstetric or unspecified, Neurologic disease, Hematologic disease, Respiratory disease, Diabetic ketoacidosis, Peritonitis or parametritis, Toxic liver disease or hepatic failure, Canadian Classification of Health Interventions, Assisted ventilation or resuscitation, Dialysis, Hysterectomy, Evacuation of incisional hemato-ma, Repair of bladder, urethra or intestine, Embolization or ligation of pelvic vessels or suturing of uterus, Blood transfusion 
population [29, 32, 34, 36, 38] excluding e.g. low birth weight or multiple births. Annual volumes and its comparators were set differently in terms of group sizes and defining births [27, 29-33, 36, 39] or deliveries/ pregnancies respectively women giving birth $[28,34,35,37$, 38 ] as basis for the calculation. While "birth" refer to the neonate, "delivery" describes the mother who is giving birth. Due to multiple pregnancies, number of deliveries is usually lower than the number of births. Unfortunately, not all studies reported both numbers, but Table 2 shows the different annual volumes in the included studies. In addition to the different annual volumes, maximum, [29, $33,36-39]$ minimum [35] and mean quantities [27, 28, $34]$ as well as university clinics (UH) [30, 32] were used as reference volumes. The analyzed outcomes included stillbirths, [31, 32, 34] perinatal/ early [29, 30, 32, 34, 37, 38 ] and neonatal mortality, [27, 31, 33-36, 39] birth by caesarean section $[30,36]$ and composite outcomes like perinatal adverse outcome [38] or maternal morbidity/ mortality [37]. Six out of thirtheen studies did not solely focus on volume-outcome relationship, but analyzed influence of geographic accessibility [37], birth at night hours [38], staffing [31], availability of facilities [31], on call arrangements [32], or birth at weekday/ weekend [39].

\section{Results of the critical appraisal}

Table 3 shows in detail that most of the included studies (12 out of 13 studies) fulfilled the majority of the queried items leading to an "acceptable" quality [27-32, 34-39]. Quality of one study was rated as "unacceptable" due to lack of comparability (missing baseline-tables, item 1.2) of the investigated groups [33].

Due to the retrospective design and other methodological reasons, some items were not applicable:

- number of participants (item 1.3)

- outcome already present before start of study (item 1.4)

- drop-out (item 1.5)

- comparison between full and lost to follow-up (item 1.6) and

- multiple measured exposure levels (item 1.12).

None of the studies fulfilled the criteria for blinding (item 1.8) and critical recognition of limited possibilities of blinding (item 1.9) in cohort studies. An externally demonstrated validity (item 1.11) and reliability (item 1.10) of the assessed outcomes was not applicable due mortality, caesarean sections or other clinical outcomes are not subjective measures.

We originally planned to perform a meta-analysis but were unable to conduct it due to definitional heterogeneities in the included studies. Additional file 5 provides a tabular overview of heterogeneities identified between the outcomes analyzed. Five studies were excluded from a pooled estimate due to singular report of the outcome maternal mortality, [28] maternal morbidity/ mortality, [37] neonatal complications, [38] missing adjustments [34, 35] and the singular use of risk ratios as estimator, [31] 99\% confidence intervals [36] or pearson correlation coefficients [39]. The remaining results for the outcomes stillbirth, $[32,34]$ perinatal/ early neonatal mortality, $[29,30,32,37,38]$ neonatal mortality $[27,33$, 39 ] and caesarean sections [30] were not comparable due to heterogeneously defined adjustment variables, populations (all births vs. predefined low risks), outcomes (e.g. undefined vs. defined) and volume-thresholds. Consequently, we summarized the results qualitatively.

\section{Effects of annual volume on neonatal outcomes}

Stillbirth was evaluated in three studies [31, 32, 34] and defined as fetal death prior to 22 [34] or 24 [31] weeks of gestation or remained undefined [32]. For hospitals with medium-sized birth volumes (1000-1999 p.a.) stillbirth odds ratio was significantly higher when compared with university hospitals [32]. Similar effects were found for hospitals with birth volumes between 1000-2999, when compared with high birth volumes ( $\geq 3000$ p.a.) [34]. However, taking all data together there was no clear volume effect on the rate of stilbirths (Fig. 2).

Perinatal or early neonatal mortality has been defined as death within the first 7 days of life $[29,30,34,38]$ or as a combined outcome [34,37]. One study did not provide a specific definitio [32]. Results were always adjusted, except for one study [34]. Whereas two studies did not report a significant volume-effect, [32, 38] four studies showed significantly higher rates of perinatal/ early neonatal mortality in hospitals with low $(\leq 1000)[29,30,34$, 37] or very low $(\leq 500)[29,37]$ birth volumes (Fig. 2) for either low risk (term infants with birthweight $>2499 \mathrm{~g}$ ) $[29,34]$ or all births [30, 37].

Neonatal mortality was defined as 28-day-, [31, 33-36, 39] or 27-day-mortality [27] in order to analyze all [31, $33-36,39]$ and/or low risk births [27, 34-36]. The majority of the studies undertook adjustments [27, 31, 33, 36]. As illustrated in Fig. 3 five [27, 33, 35, 36, 39] out of seven studies reported significant volume effect estimates with neonatal mortality being higher in hospitals with lower [33] or higher annual birth volumes [27, 35, 36, 39]. The remaining two studies reported non-significant volumeoutcome effects [31, 34].

The study from Moster et al. reported higher neonatal mortality rates in hospitals with low birth volumes however, was lacking comparability between groups due to missing baseline-table and thus, quality was rated 


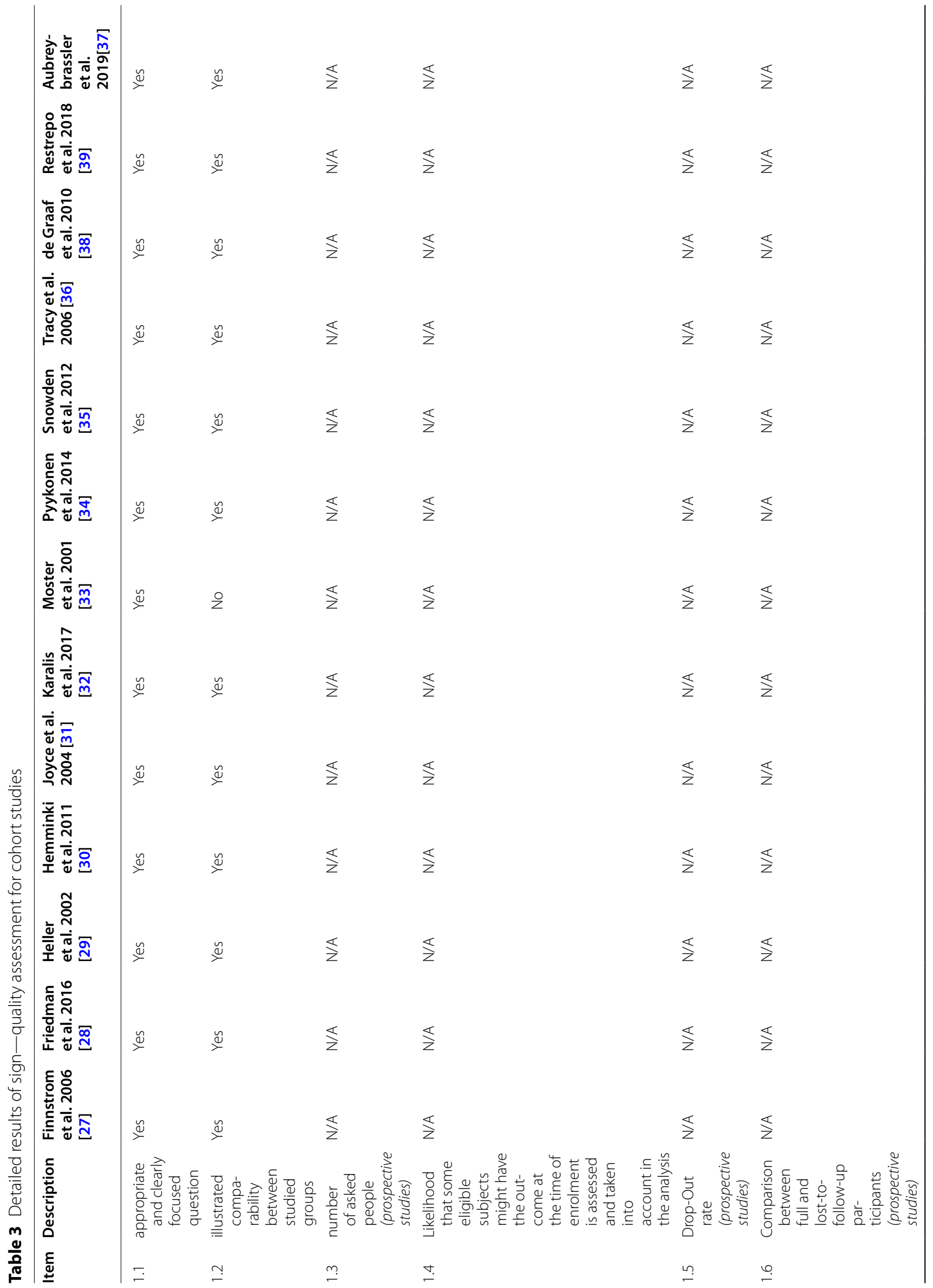




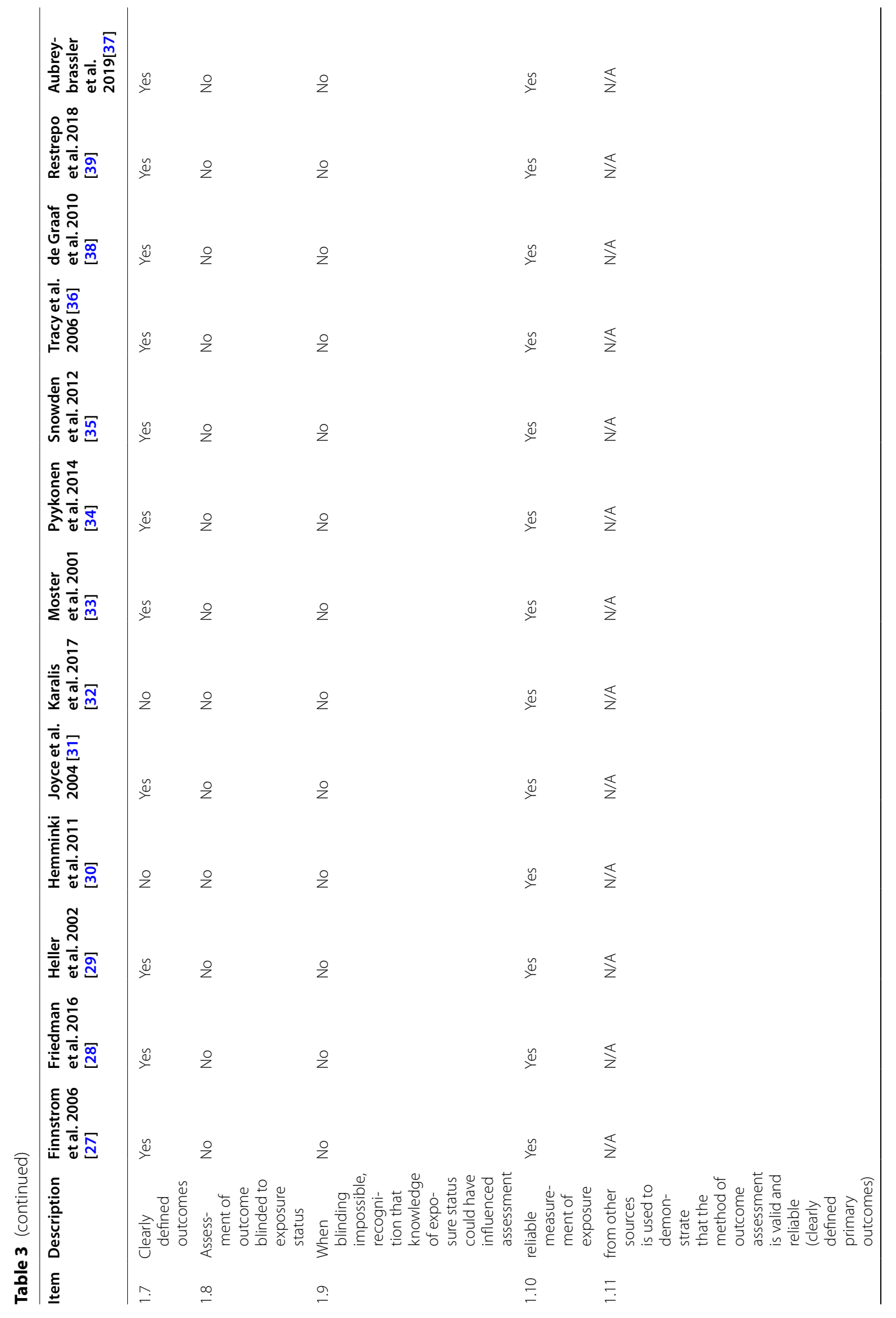




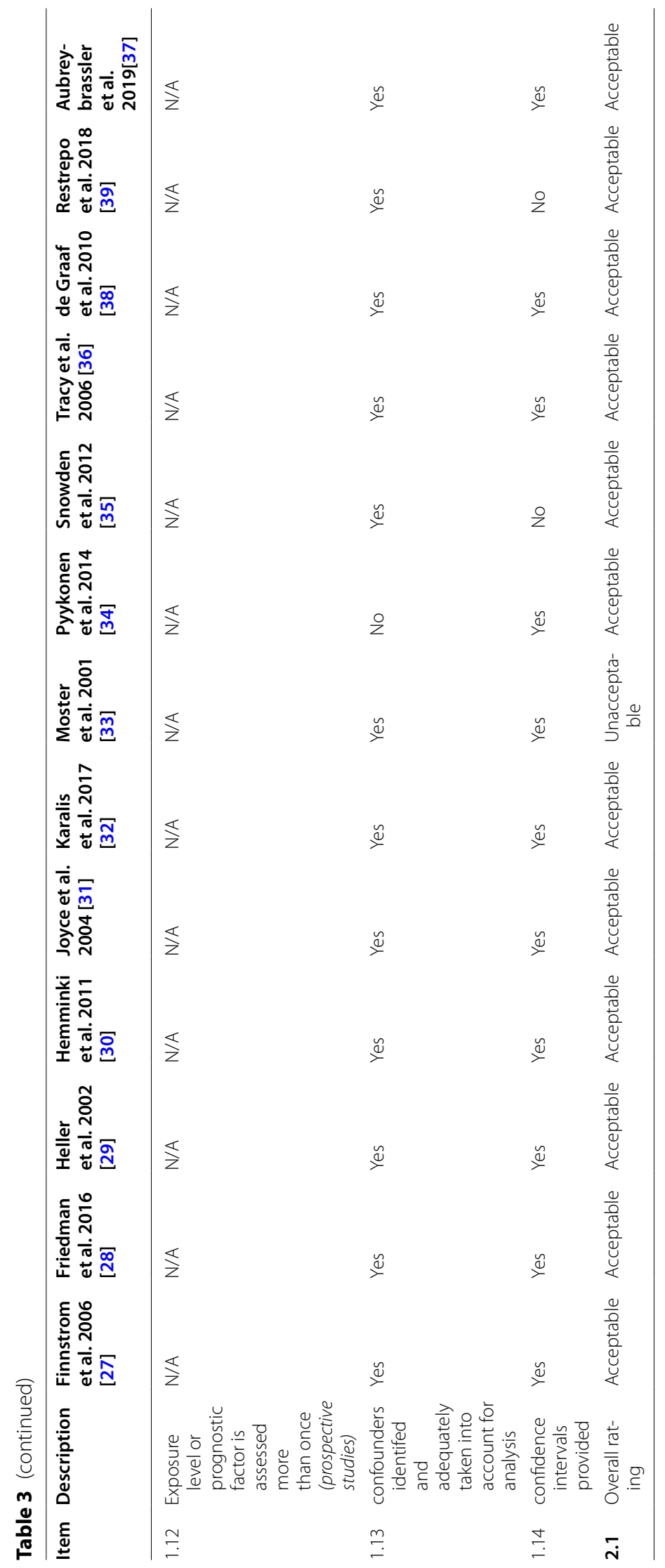


"unacceptable" [33]. In conclusion, methodically limitations hinder conclusive statements regarding the effect of birth volume on neonatal mortality.

Neonatal complications were reported in one study as a combined outcome ("perinatal adverse outcome") including stillbirths, death $\leq 7$ days, 5-min Apgar $<7$ and a transfer to a neonatal intensive care unit in singleton births. Non-monotonous, significantly higher odds ratios of neonatal complications were reported for units with 750-999 and 1500-1749 births (Fig. 3) compared to at least 1750 births per anno [38].

\section{Effects of annual birth volume on maternal outcomes}

Adjusted maternal mortality was reported as failing attempts to resuscitate women with severe complications during birth [28]. The volume-outcome relationships were reported to be non-monotonous in general with lower and higher relative risks of maternal mortality in lower (50) and higher annual birth volumes ( $\geq 2250$ 7500) [28].

Adjusted maternal complications were reported in two studies as a combined outcome consisting of maternal mortality and different morbidy outcomes in all births $[28,37]$. In a Canadian study the odds ratio were reported to be significantly higher in hospitals with $\leq 1000$ births p.a [37]. However, a study from the US reported nonmonotonous results with higher risk ratios in hospitals with high (2500) and low (50) annual birth volumes. Without providing results, the relative risks of maternal complications remained higher with a further increase in birth volume [28]. In conclusion, no conclusive statement regarding the impact of birth volume on maternal complication is possible due to contradicting study results as shown in Fig. 4.

An adjusted rate of delivery via caesarean section was reported in two studies [30,36]. Hemminki et al. reported a significantly higher rate of caesarean sections in "small-hospital-areas" with less than 750 births per year compared to "capital areas" [30]. In contrast, Tracy et al. reported a significantly lower rate of caesarean sections in hospitals with $\leq 500$ births [36]. Thus, contradicting study results do not allow conclusions regarding volume-effects on mode of delivery (Fig. 4).

In summary, most studies suggested a volume-outcome relationship on perinatal / early neonatal mortality and however reported either insignificant, non-monotonous or conflicting results regarding volume effects on the remaining outcomes.

\section{Discussion}

This systematic review on the effects of hospital case volume on the safety and outcomes of infants classified as being on low risk births has tremendous public health impact, as births of children are so frequent and such an important life event. There is evidence already for high risk births and many other conditions such as preterm birth [1, 23], pediatric intensive care [71] or pediatric heart surgery [72] that hospitals with more experience and higher case numbers provide better healthcare indicated by better health outcomes of patients being treated there. We therefore speculated that higher birth volumes of hospitals were also related to better outcomes in births of low risk or all infants. These studies reported on mortality (stillbirths, perinatal, neonatal, maternal), morbidity (neonatal, maternal) and mode of delivery. Readmissions and developmental delays were not reported. Initially, a pooled estimate was intended. Heterogenities within the definitions and presentations of characteristics led to the decision not to perform a pooled estimate. Therefore, the results were synthesized qualitatively focusing on volume-outcome in general and especially in terms of lower annual birth volumes $(\leq 1000)$. The heterogeneous results reported by two studies in different groups were not discussed by the study authors [30,34] but might be caused by effect modifications.

While a possible effect of volume on early neonatal mortality was found to be consistent when statistical significance was reached, the influence of birth volume on other outcomes was less consistent. The reason for these inconsistencies has to be discussed. It could be assumed, that inconsistencies can be explained at a systemic level reflecting differences between national health care systems with variations in budgeting, access, geographical and historical conditions. One study included in this review showed differences of caesarean sections in dependence to hospital birth volume [36]. Several explanations could be discussed. It is possible that this could be an effect of perinatal regionalization treating high risk pregnancies in high birth volume hospitals leading into the need of surgical birth interventions. On the other hand, the appropriateness and need for the indication of e.g. epidural anesthesia was also discussed with reference to hospital ownership [15]. However, to further analyze the sensitive topic of appropriateness, qualitative research with primary data is needed. Due to the lack of detail information and

(See figure on next page.)

Fig. 2 Stillbirths and early/ perinatal mortality. Legend: [...] BW, age, parity, born outside clinic, birth planned and documented clinic, mode of delivery, born before arrival at clinic, time of birth, congenital anomaly/ malformation. [... $]^{2}$ age, parity, socio-economic position. [.... $]^{3}$ age, parity, mode of delivery, ethnicity, calendar year trend. [... $]^{4}$ gender, Eclampsia, Premature rupture of membranes, Oligohydramnios, Abruptio placentae, Prolapsed umbilical cord, Noxious influences transmitted via placenta/ breast milk, Congenital anomalies, Hydrops fetalis, Other maternal conditions 


\section{Outcome stillbirths}

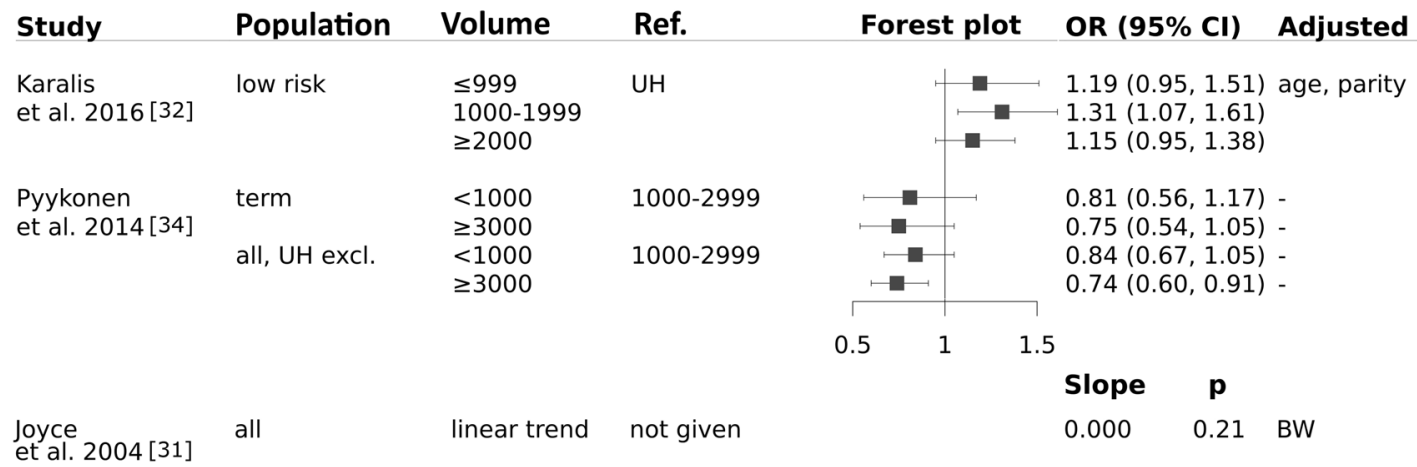

Outcome perinatal and early neonatal mortality

\begin{tabular}{|c|c|c|c|c|c|c|}
\hline Study & Population & Volume & Ref. & Forest plot & OR $(95 \% \mathrm{Cl})$ & Adjusted \\
\hline $\begin{array}{l}\text { Heller } \\
\text { et al. } 2002 \text { [29] }\end{array}$ & $\begin{array}{l}B W>2500 \mathrm{~g} \\
\{\mathrm{BW}>2500 \mathrm{~g} \\
+ \text { term }\}\end{array}$ & $\begin{array}{l}<501 \\
501-1000 \\
1001-1500 \\
<501 \\
501-1000 \\
1001-1500\end{array}$ & $\begin{array}{l}>1500 \\
>1500\end{array}$ & $=$ & $\begin{array}{l}3.48(2.62,4.62) \\
1.84(1.45,2.35) \\
1.43(1.00,2.03) \\
3.48(2.50,4.84) \\
1.87(1.38,2.55) \\
1.41(1.01,1.97)\end{array}$ & $\begin{array}{l}\text { GA, }[\ldots]^{1} \\
\text { GA, }[\ldots]^{1}\end{array}$ \\
\hline $\begin{array}{l}\text { Pyykonen } \\
\text { et al. } 2014 \text { [34] }\end{array}$ & $\begin{array}{l}\text { all, UH excl. } \\
\text { term, UH excl. } \\
\text { all, UH excl. } \\
\text { term, UH excl. }\end{array}$ & $\begin{array}{l}<1000 \\
\geq 3000 \\
<1000 \\
\geq 3000 \\
<1000 \\
\geq 3000 \\
<1000 \\
\geq 3000\end{array}$ & $\begin{array}{r}1000-2999 \\
1000-2999 \\
1000-2999 \\
1000-2999\end{array}$ & 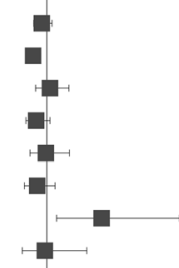 & $\begin{array}{l}0.90(0.74,1.10) \\
0.73(0.61,0.88) \\
1.06(0.78,1.43) \\
0.79(0.59,1.06) \\
0.98(0.67,1.44) \\
0.81(0.56,1.16) \\
2.07(1.19,3.59) \\
0.96(0.52,1.78)\end{array}$ & - \\
\hline $\begin{array}{l}\text { Hemminki } \\
\text { et al. } 2011 \text { [30] }\end{array}$ & $\begin{array}{l}\text { all ('04-'08) } \\
\{B W>2499 g \\
(' 04-' 08)\}\end{array}$ & $\begin{array}{l}<750 \\
750-1499 \\
\geq 1500 \\
<750 \\
750-1499 \\
\geq 1500\end{array}$ & UH & $=$ & $\begin{array}{l}1.48(1.15,1.90) \\
1.93(1.58,2.35) \\
1.67(1.44,1.92) \\
0.87(0.61,1.23) \\
1.16(0.87,1.56) \\
0.94(0.76,1.16)\end{array}$ & $\begin{array}{l}B W,[\ldots]^{2} \\
B W,[\ldots]^{2}\end{array}$ \\
\hline $\begin{array}{l}\text { Karalis } \\
\text { et al. } 2016 \text { [32] }\end{array}$ & low risk & $\begin{array}{l}\leq 999 \\
1000-1999 \\
\geq 2000\end{array}$ & $\mathrm{UH}$ & $\square^{+}$ & $\begin{array}{l}2.11(0.97,4.56) \\
1.72(0.81,3.66) \\
1.17(0.56,2.42)\end{array}$ & age, parity \\
\hline $\begin{array}{l}\text { de Graaf } \\
\text { et al. } 2010 \text { [38] }\end{array}$ & singleton & $\begin{array}{l}<750 \\
750-999 \\
1000-1249 \\
1250-1499 \\
1500-1749\end{array}$ & $\geq 1750$ & 2 & $\begin{array}{l}1.08(0.83,1.40) \\
0.89(0.70,1.14) \\
0.99(0.81,1.20) \\
1.01(0.83,1.23) \\
0.97(0.81,1.18)\end{array}$ & $G A,[\ldots]^{3}$ \\
\hline $\begin{array}{l}\text { Aubrey-Brassler } \\
\text { et al. } 2019 \text { [37] }\end{array}$ & all & $\begin{array}{l}\text { no reg. ser. } \\
1-49 \\
50-99 \\
100-199 \\
200-499 \\
500-999 \\
1000-2499\end{array}$ & $>2500$ & 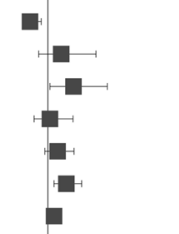 & $\begin{array}{l}0.65(0.50,0.87) \\
1.26(0.82,1.94) \\
1.50(1.04,2.16) \\
1.04(0.73,1.49) \\
1.19(0.94,1.51) \\
1.36(1.12,1.66) \\
1.12(1.01,1.24)\end{array}$ & BW, $[\ldots]^{4}$ \\
\hline
\end{tabular}

Fig. 2 (See legend on previous page.) 


\section{Outcome neonatal mortality}

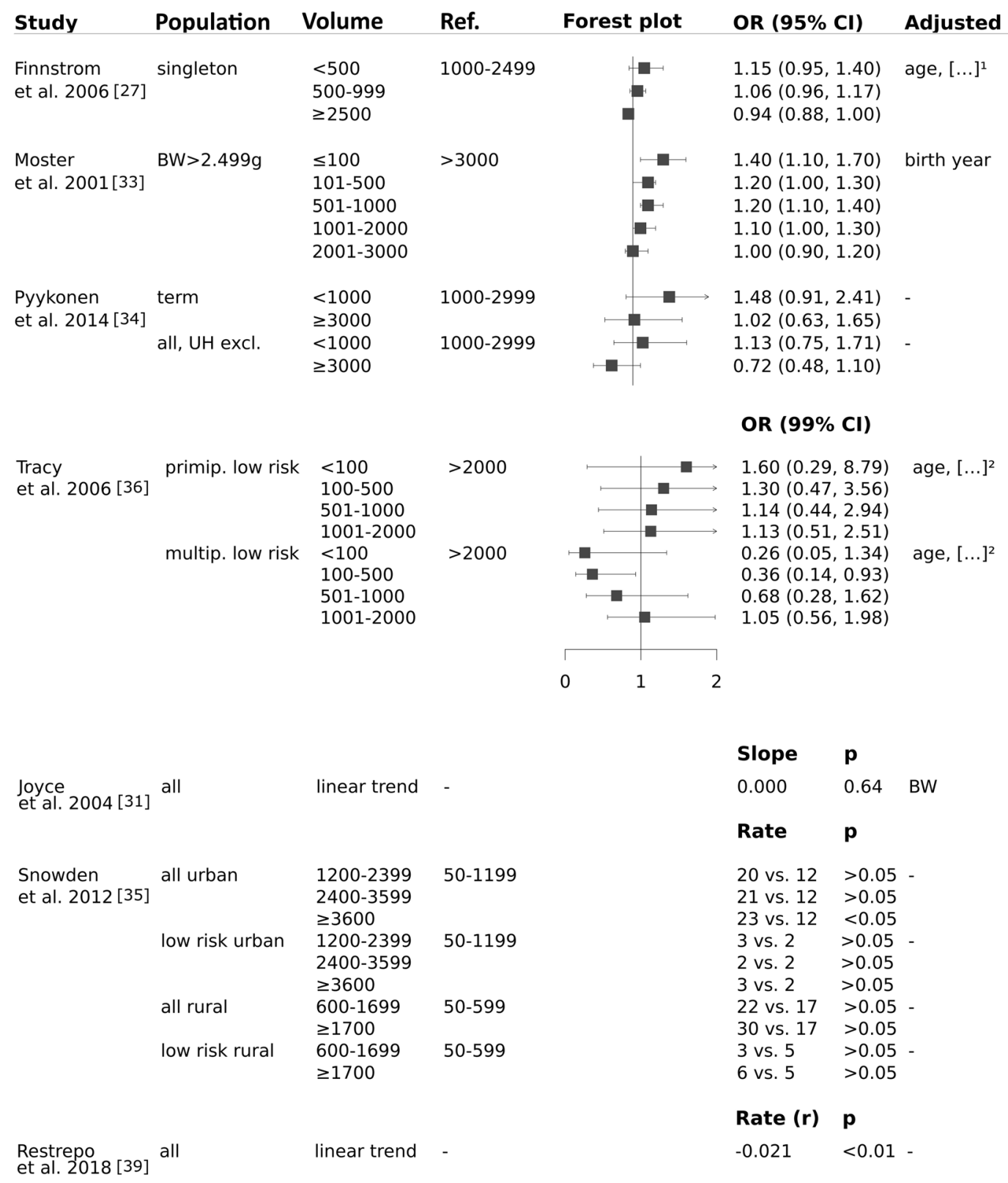

Outcome neonatal complications

\begin{tabular}{|c|c|c|c|c|c|}
\hline Population & Volume & Ref. & Forest plot & OR $(95 \% \mathrm{CI})$ & Adjusted \\
\hline $\begin{array}{l}\text { de Graaf singleton } \\
\text { et al. 2010[38] }\end{array}$ & $\begin{array}{l}<750 \\
750-999 \\
1000-1249 \\
1250-1499 \\
1500-1749\end{array}$ & $\geq 1750$ & 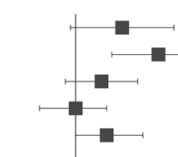 & $\begin{array}{l}1.09(0.99,1.19) \\
1.16(1.07,1.26) \\
1.05(0.98,1.12) \\
1.00(0.93,1.06) \\
1.06(1.00,1.13)\end{array}$ & $\left\{\begin{array}{l}\mathrm{GA}, \text { age },[\ldots]^{3} \\
\end{array}\right.$ \\
\hline
\end{tabular}

Fig. 3 Neonatal complications and neonatal mortality. Legend: [... $]^{1}$ parity, GA, year of birth, smoking, parental cohabitation, maternal BMI. [... $]^{2}$ insurance status, maternal Aboriginal or Torres Strait Island status, maternal residential area. [... $]^{3}$ parity, mode of delivery, ethnicity, calendar year trend 
data quality, routine data must be used with caution in order to avoid over- or misinterpretation [73].

With respect to a risk appropriate care, perinatal regionalization policies vary in terms of general organization, obligation and practice [2, 3]. At the provider level birth/ delivery volumes may be only one covariate between several others such as time of birth, $[38,39,70]$ personnel and material resources, [31, 32, 74] work environment [75] or qualifications [76] influencing the outcome of newborns indicated by studies included in this review.

Despite of lower early neonatal mortality in hospitals with high annual birth volume, closure of low volume institutions has to be considered very carefully, since reults have been discussed controversially. Some studies suggest a higher rate of unplanned out-of-hospital births [77] and an increased rate of neonatal mortality and stillbirths immediately after closures [58]. Furthermore, an increased rate of adverse birth outcomes [78] and higher stress/ anxiety levels of pregnant women were reported in large rural landscapes with long distances to access perinatal care [79]. Other studies report significantly lower rates of stillbirths and neonatal mortality in both rural and urban regions after closing maternity units [41].

The heterogeneous definitions identified in this and other systematic reviews [80] support the need for a standardized terminology of outcomes, populations and volume-thresholds. The definition of core-outcome sets (COS) would help to overcome that issue. The uniform terminology enables the design of comparable studies and forms the basis for the development of an international perinatal register. A homogeneously created perinatal register would allow individual patient data meta-analyses providing promising results as it has been shown for other indications $[81,82]$.

Overall most (12/13) of the included studies showed an "acceptable" quality as it is the highest rating for retrospective studies [26]. One study lacked an illustrated comparability of the study groups that led to "unacceptable" quality as it strongly limits transparency. None of the studies blinded the assesors nor was a report of nonblinding included. Nevertheless, we considered the studies as meaningful for interpretation because the assessed outcomes are difficult to manipulate and therefore the lack of blinding seems to be a minor weakness.

\section{Strengths and Limitations}

This is the first systematic review explicitly assessing birth volume effects on neonatal outcome in low risk births. The review used transparent methods (independent screening, search strategy), was officially registered, is based on two major databases (combined with extensive hand search and expert panel for highlighting relevant literature) and followed common critical appraisal requirements of systematic reviews determined by AMSTAR 2 [83]. The high inter-rater-reliability ensures comprehensibility. The time and national restriction in the inclusion criteria could be interpreted as a limitation. However, it is well known that international comparisons must take into account the efficacy of health care systems [84, 85]. Thus, we used neonatal mortality rates as an indicator of this efficacy. With respect to the time restriction starting with publication in 2000, this review considered the decline of neonatal mortality and the development of perinatal care in since 1990 [86]. On the other hand, some of the studies have long past study periods (19672012) and intervals (1 to 29 years), indicating that the publication date did not work perfectly well as a delimiter to represent only current perinatal care. Almost every study showed an "acceptable" quality with retrospectively collected routine or register data.

\section{Conclusion}

The aim of that review was originally to investigate volume-outcome associations in a comparatively low-risk birth cohort. With the exception of 7-day mortality, the review revealed heterogeneous results and major differences in the conception and definitions of the included studies.The qualitative synthesis of the studies indicated increased rates of early neonatal mortality $(<7 \mathrm{~d})$ in hospitals with birth volumes below 1000 or 500 births per anno when statistical significance was given. With respect to stillbirths, neonatal mortality, maternal mortality, caesarean section and neonatal and maternal complications the studies included reported inconclusive or insignificant results. Referring to the heterogeneously conducted study concepts in terms of assessed populations, volume-thresholds and outcomes, we recommend the development and use of internationally consented core-outcome sets to provide a homogenous definitional basis in future studies. A uniform

\footnotetext{
(See figure on next page.)

Fig. 4 Maternal mortality, maternal complications and caesarean sections. Legend: [...]1: race, hospital, year, comorbidity index, insurance status, household income, hospital teaching, hospital bed size, hospital region, hospital ownership, hospital location. [...]2: GA, CS, Median income, Education rate, Aboriginal population, Unemployment rate, Minority, Statistical area classification, Travel Distance, Delivery hospital volume, Hospital level, HIV, Type 1/2 DM, Gestational/ other/ unspecified DM, Cystic fibrosis, Rheumatic heart disease, Hypertension, Ischemic heart disease, Pulmonary hypertension, SLE, Chronic renal disease, Twins/ multiple gestation, Previous CS. [...]3: race, hospital, year, comorbidity index, insurance status, household income, hospital teaching, hospital bed size, hospital region, hospital ownership, hospital location. [...]4: insurance status, maternal Aboriginal or Torres Strait Island status, maternal residential area. [...]5: parity, smoking, socio-economic position
} 


\section{Outcome maternal mortality

\begin{tabular}{|c|c|c|c|c|c|c|}
\hline Study & Population & Volume & Ref. & Forest plot & $\operatorname{RR}(95 \% \mathrm{Cl})$ & Adjusted \\
\hline $\begin{array}{l}\text { Friedman } \\
\text { et al. } 2016[28]\end{array}$ & all & $\begin{array}{l}50 \\
1500 \\
2250\end{array}$ & 1000 & - & $\begin{array}{r}2.02(1.95,2.08 \\
0.90(0.84,0.96 \\
1.14(1.05,1.24\end{array}$ & ) age, $[\ldots]^{1}$ \\
\hline
\end{tabular}

Outcome maternal complications

\begin{tabular}{|c|c|c|c|c|c|c|}
\hline Study & Population & Volume & Ref. & Forest plot & OR $(95 \% \mathrm{CI})$ & Adjustec \\
\hline \multirow[t]{2}{*}{$\begin{array}{l}\text { Aubrey-Brassler } \\
\text { et al. } 2019 \text { [37] }\end{array}$} & all & $\begin{array}{l}\text { no reg. ser. } \\
1-49 \\
50-99 \\
100-199 \\
200-499 \\
500-999 \\
1000-2499\end{array}$ & $\geq 2500$ & (a) & $\begin{array}{l}0.98(0.88,1.09) \\
1.12(0.92,1.36) \\
1.48(1.27,1.72) \\
1.34(1.17,1.53) \\
1.34(1.22,1.48) \\
1.26(1.16,1.38) \\
0.90(0.86,0.95)\end{array}$ & 更 \\
\hline & & & & & $\operatorname{RR}(95 \% \mathrm{CI})$ & \\
\hline \multirow[t]{2}{*}{$\begin{array}{l}\text { Friedman } \\
\text { et al. } 2016 \text { [28] }\end{array}$} & all & $\begin{array}{l}50 \\
1250 \\
2500\end{array}$ & 1000 & $\square$ & $\begin{array}{l}1.40(1.39,1.40) \\
0.98(0.98,0.99) \\
1.34(1.31,1.36)\end{array}$ & age, $[\ldots]^{3}$ \\
\hline & & & & $\begin{array}{cc} & \\
0.7 & 1\end{array}$ & & \\
\hline
\end{tabular}

\section{Outcome caesarean sections}

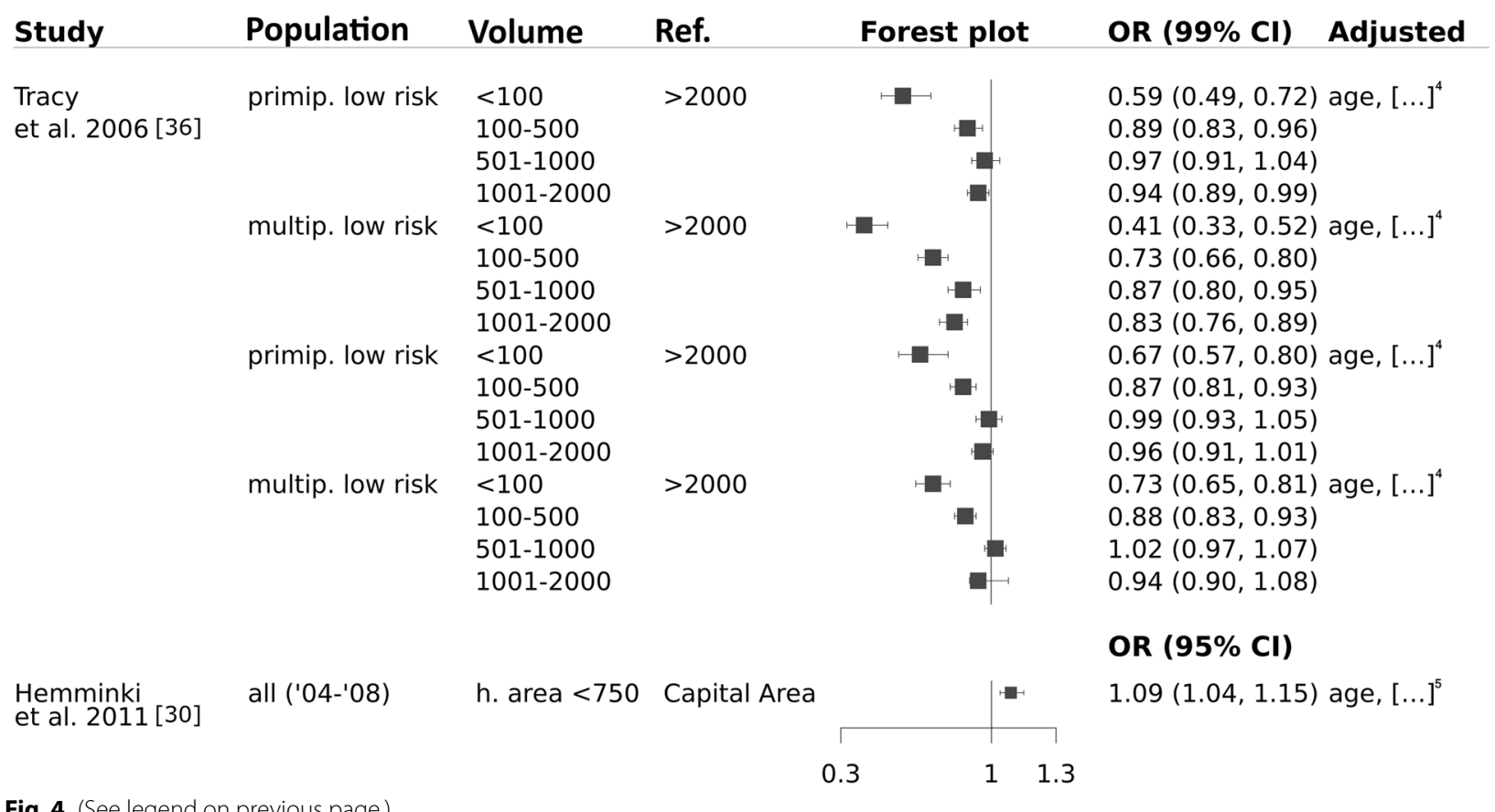


terminology would enable a homogenously conceived internationally birth register for individual patient data meta analyses. Based on these data, strengths and weaknesses of different perinatal settings could be investigated using a common terminology of population, volume and outcome.

\section{Abbreviations}

AUS: Australia; B-A: Before-After-Design; BMI: Body mass index; BW: Birth weight; CA: Canada; Cl: Confidence interval; CS: Caesarean sections; d: Days; DM: Diabetes mellitus; FIN: Finland; GER: Germany; GA: Gestational age; h: Hospital; HIV: Humane immunodeficiency virus; NICU: Neonatal intensive care unit; NO: Norway; OR: Odds ratio; sv. morb: Severe morbidity; RR: Relative risk; p.a: Per anno; POR: Portugal; SCD: Sudden cardiac death; SIDS: Sudden infant death syndrome; SWE: Sweden; SLE: Systemic lupus erythematosus; UH: University hospital; wk: Week; UK: United Kingdom; US: United States.

\section{Supplementary Information}

The online version contains supplementary material available at https://doi. org/10.1186/s12884-021-03988-y.

\section{Additional file 1.}

Additional file 2.

Additional file 3 .

Additional file 4.

Additional file 5 .

\section{Acknowledgements}

We would like to thank Peter Hellmund for his help in creating the Figures 2, 3 and 4 and Rainer Rossi for serving as an expert to highlight possible relevant literature.

\section{Authors' contributions}

JS, JM and FW conceptualised the review. FW developed the search strategy. FW, DK and AB performed the literature search, data collection and analysis. FW drafted the manuscript. MR and JS contributed to the data synthesis and interpretation. All authors contributed substantially to the production and editing of the final manuscript. The author(s) read and approved the final manuscript.

\section{Funding}

Open Access funding enabled and organized by Projekt DEAL. This investigator-initiated systematic review was supported by an instiutional grant from Federation of Local Health Insurance Funds. Open Access Funding by the Publication Fund of the TU Dresden.

\section{Availability of data and materials}

All data generated or analysed during this study are included in this published article [and its supplementary information files].

\section{Declarations}

\section{Ethics approval and consent to participate}

N/A

\section{Consent for publication}

N/A

\section{Competing interests}

The authors declare that they have no competing interests.

\section{Author details}

${ }^{1}$ Center for Evidence-Based Healthcare, Medical Faculty Carl Gustav Carus, TU Dresden, Fetscherstraße 74, 01307 Dresden, Germany. ${ }^{2}$ Quality and Medical Risk Management, University Hospital Carl, Gustav Carus, Fetscherstraße 74, 01307 Dresden, Germany. ${ }^{3}$ Institute of Health and Nursing Science, Medical Faculty, Martin Luther University Halle-Wittenberg, Postfach 302, 06097 Halle, Saale, Germany. ${ }^{4}$ Federation of Local Health Insurance Funds, Clinical Care, Rosenthaler Str. 31, 10178 Berlin, Germany. ${ }^{5}$ Department for Neonatology and Pediatric Intensive Care, University Hospital Carl Gustav Carus, Technische Universität Dresden, Fetscherstraße 74, 01307 Dresden, Germany. ${ }^{6}$ Medical Faculty Carl Gustav Carus, Saxony Center for Feto-Neonatal Health, TU Dresden, Fetscherstraße 74, 01307 Dresden, Germany.

Received: 8 February 2021 Accepted: 2 July 2021

Published online: 27 July 2021

\section{References}

1. Lasswell SM, Barfield WD, Rochat RW, Blackmon L. Perinatal regionalization for very low-birth-weight and very preterm infants a meta-analysis. JAMA. 2010;304(9):992-1000.

2. Zeitlin J, Papiernik E, Breart G. Regionalization of perinatal care in Europe. Semin Neonatol. 2004;9(2):99-110.

3. Kunz SN, Phibbs CS, Profit J. The changing landscape of perinatal regionalization. Semin Perinatol. 2020;44(4):151241.

4. Walther F, Küster DB, Bieber A, Rüdiger M, Malzahn J, Schmitt J, Deckert S. Impact of regionalisation and case-volume on neonatal and perinatal mortality: an umbrella review. BMJ Open. 2020;10(9):e037135.

5. Gravett MG, Rubens CE, Nunes TM. the GRG: Global report on preterm birth and stillbirth (2 of 7): discovery science. BMC Pregnancy Childbirth. 2010;10(1):S2.

6. Lawn JE, Gravett MG, Nunes TM, Rubens CE, Stanton C. the GRG: Global report on preterm birth and stillbirth (1 of 7): definitions, description of the burden and opportunities to improve data. BMC Pregnancy Childbirth. 2010;10(1):S1.

7. Jolly M, Sebire N, Harris J, Robinson S, Regan L. The risks associated with pregnancy in women aged 35 years or older. Hum Reprod. 2000;15(11):2433-7.

8. Lawn JE, Cousens S, Zupan J. 4 million neonatal deaths: when? Where? Why? Lancet. 2005;365(9462):891-900.

9. Luke B, Brown MB. Elevated risks of pregnancy complications and adverse outcomes with increasing maternal age. Hum Reprod. 2007;22(5):1264-72.

10. Ronsmans C, Graham WJ. Maternal mortality: who, when, where, and why. Lancet. 2006;368(9542):1189-200.

11. Holness N. High-Risk Pregnancy. Nurs Clin North Am. 2018;53(2):241-51.

12. Jordan RG, Murphy PA. Risk Assessment and Risk Distortion: Finding the Balance. J Midwifery Womens Health. 2009;54(3):191-200.

13. Simpson KR. Minimizing Unnecessary Interventions During Labor and Birth. MCN Am J Maternal/Child Nurs. 2017;42(4):240.

14. Simpson KR, Thorman KE. Obstetric "Conveniences": Elective Induction of Labor, Cesarean Birth on Demand, and Other Potentially Unnecessary Interventions. J Perinatal Neonatal Nurs. 2005;19(2):134-44.

15. Tracy SK, Tracy MB. Costing the cascade: estimating the cost of increased obstetric intervention in childbirth using population data. BJOG Int J Obstetr Gynaecol. 2003;110(8):717-24.

16. Duffy JMN, Rolph R, Gale C, Hirsch M, Khan KS, Ziebland S, McManus RJ, On behalf of the International Collaboration to Harmonise Outcomes in P-e. Core outcome sets in women's and newborn health: a systematic review. BJOG Int J Obstetr Gynaecol. 2017;124(10):1481-9.

17. Egan AM, Galjaard S, Maresh MJA, Loeken MR, Napoli A, Anastasiou E, Noctor E, de Valk HW, van Poppel M, Todd M, et al. A core outcome set for studies evaluating the effectiveness of prepregnancy care for women with pregestational diabetes. Diabetologia. 2017;60(7):1190-6.

18. van 't Hooft J, Duffy JM, Daly M, Williamson PR, Meher S, Thom E, Saade GR, Alfirevic Z, Mol BW, Khan KS. A Core Outcome Set for Evaluation of Interventions to Prevent Preterm Birth. Obstet Gynecol. 2016;127(1):49-58. 
19. Devane D, Begley CM, Clarke M, Horey D, Oboyle C. Evaluating Maternity Care: A Core Set of Outcome Measures. Birth. 2007;34(2):164-72.

20. Webbe J, Brunton G, Ali S, Duffy JMN, Modi N, Gale C. Developing, implementing and disseminating a core outcome set for neonatal medicine. BMJ Paediatrics Open. 2017;1(1):e000048.

21. Nijagal MA, Wissig S, Stowell C, Olson E, Amer-Wahlin I, Bonsel G, Brooks A, Coleman M, Devi Karalasingam S, Duffy JMN, et al. Standardized outcome measures for pregnancy and childbirth, an ICHOM proposal. BMC Health Serv Res. 2018:18(1):953-953.

22. Moher D, Liberati A, Tetzlaff J, Altman DG, The Prisma Group. Preferred Reporting Items for Systematic Reviews and Meta-Analyses: The PRISMA Statement. PLOS Med. 2009;6(7):e1000097.

23. Walther F, Küster D, Bieber A, Schmitt J. The impact of regionalization and case-volume of general perinatal care on neonatal and perinatal mortality: a systematic review. PROSPERO: International prospective register of systematic reviews. CRD42018095289 [https://www.crd.york.ac.uk/prosp ero/display_record.php?RecordID=95289]

24. UN Interagency Group for Child Mortality Estimation: Levels and Trends in Child Mortality Report. 2017;2017:36.

25. Byrt T, Bishop J, Carlin JB. Bias, prevalence and kappa. J Clin Epidemiol. 1993:46(5):423-9.

26. Scottish Intercollegiate Guidelines Network (SIGN). Checklist for cohort studies. https://www.sign.ac.uk/assets/checklist_for_cohort_studies.rtf.

27. Finnstrom O, Berg G, Norman A, Otterblad Olausson P. Size of delivery unit and neonatal outcome in Sweden. A catchment area analysis. Acta Obstetricia et Gynecologica Scand. 2006;85(1):63-67.

28. Friedman AM, Ananth CV, Huang Y, D'Alton ME, Wright JD. Hospital delivery volume, severe obstetrical morbidity, and failure to rescue. Am J Obstet Gynecol. 2016;215(6):795.e791-795.e714.

29. Heller G, Richardson DK, Schnell R, Misselwitz B, Kunzel W, Schmidt S. Are we regionalized enough? Early-neonatal deaths in low-risk births by the size of delivery units in Hesse, Germany 1990-1999. Int J Epidemiol. 2002;31(5):1061-8.

30. Hemminki E, Heino A, Gissler M. Should births be centralised in higher level hospitals? Experiences from regionalised health care in Finland. BJOG Int J Obstetr Gynaecol. 2011;118(10):1186-95.

31. Joyce R, Webb R, Peacock JL. Associations between perinatal interventions and hospital stillbirth rates and neonatal mortality. Arch Dis Child Fetal Neonatal Ed. 2004;89(1):F51-56.

32. Karalis E, Gissler M, Tapper A-M, Ulander V-M. Effect of hospital size and on-call arrangements on intrapartum and early neonatal mortality among low-risk newborns in Finland. Eur J Obstet Gynecol Reprod Biol. 2016;198:116-9.

33. Moster D, Lie RT, Markestad T. Neonatal mortality rates in communities with small maternity units compared with those having larger maternity units. BJOG Int J Obstetr Gynaecol. 2001;108(9):904-9.

34. Pyykonen A, Gissler M, Jakobsson M, Petaja J, Tapper AM. Determining obstetric patient safety indicators: the differences in neonatal outcome measures between different-sized delivery units. BJOG Int J Obstetr Gynaecol. 2014;121(4):430-7.

35. Snowden JM, Cheng YW, Kontgis CP, Caughey AB. The association between hospital obstetric volume and perinatal outcomes in California. Am J Obstet Gynecol. 2012;207(6):478.e471-477.

36. Tracy SK, Sullivan E, Dahlen H, Black D, Wang YA, Tracy MB. Does size matter? A population-based study of birth in lower volume maternity hospitals for low risk women. BJOG Int J Obstetr Gynaecol. 2006;113(1):86-96.

37. Aubrey-Bassler FK, Cullen RM, Simms A, Asghari S, Crane J, Wang PP, Godwin M. Population-based cohort study of hospital delivery volume, geographic accessibility, and obstetric outcomes. Int J Gynecol Obstet. 2019;146(1):95-102

38. de Graaf JP, Ravelli ACJ, Visser GHA, Hukkelhoven C, Tong WH, Bonsel GJ, Steegers EAP. Increased adverse perinatal outcome of hospital delivery at night. BJOG Int J Obstetr Gynaecol. 2010;117(9):1098-107.

39. Restrepo E, Hamilton P, Liu F, Mancuso P. Relationships Among Neonatal Mortality, Hospital Volume, Weekday Demand, and Weekend Birth. Can J Nurs Res. 2018:50(2):64-71.

40. Adams N, Tudehope D, Gibbons KS, Flenady V. Perinatal mortality disparities between public care and private obstetrician-led care: a propensity score analysis. BJOG Int J Obstetr Gynaecol. 2018;125(2):149-58.
41. Allen VM, Jilwah N, Joseph KS, Dodds L, O'Connell CM, Luther ER, Fahey TJ, Attenborough R, Allen AC. The influence of hospital closures in Nova Scotia on perinatal outcomes. JOGC. 2004;26(12):1077-85.

42. Badheka A, Rampa S, Wang T, Nalliah R, Caplin J, Allareddy V. Neonatal infections in Hospitals: Nationwide prevalence and outcomes. Crit Care Med. 2019;47(Supplement 1):808.

43. Clapp MA, James KE, Bates SV, Kaimal AJ. Patient and Hospital Factors Associated With Unexpected Newborn Complications Among Term Neonates in US Hospitals. JAMA Network Open. 2020;3(2):e1919498.

44. Engjom H, Morken NH, Hoydal E, Norheim OF, Klungsoyr K. Obstetric health system structure and perinatal outcomes in Norway. Int I Gynecol Obstet. 2015;131(SUPPL. 5):E487-8.

45. Engjom H, Moster D, Morken NH, Hoydahl E, Norheim OF, Klungsoyr K. Perinatal mortality and health system structure in Norway-a populationbased registry study. BJOG Int J Obstetr Gynaecol. 2016;123(Supplement 2):11.

46. Filipovic-Grcic B, Kniewald H, Rodin U, Grizelj R, Stipanovic-Kastelic J, Ninkovic D, Gveric-Ahmetasevic S, Stanojevic M, Furlan IA, Peter B, et al. Patterns of newborns' deaths to discharge from hospital in Croatia in the year 2011. Gynaecologia et Perinatologia. 2012;21(SUUPL.1):150-6.

47. Grytten J, Monkerud L, Skau I, Sorensen R. Regionalization and local hospital closure in Norwegian maternity care-the effect on neonatal and infant mortality. Health Serv Res. 2014;49(4):1184-204.

48. Heller G, Schnell R, Richardson DK, Misselwitz B, Schmidt S. [Assessing the impact of delivery unit size on neonatal survival: estimation of potentially avoidable deaths in Hessen, Germany, 1990-2000]. Hat die Grosse der Geburtsklinik Einfluss auf das neonatale Uberleben? Schatzung von "vermeidbaren" Todesfallen in Hessen 1990-2000. 2003;128(13):657-62.

49. Homer CSE, Thornton C, Scarf VL, Ellwood DA, Oats JJN, Foureur MJ, Sibbritt D, McLachlan HL, Forster DA, Dahlen HG. Birthplace in New South Wales, Australia: an analysis of perinatal outcomes using routinely collected data. BMC Pregnancy Childbirth. 2014;14:206.

50. Hughes S, Zweifler JA, Garza A, Stanich MA. Trends in rural and urban deliveries and vaginal births: California 1998-2002. J Rural Health. 2008;24(4):416-22.

51. Hurtado Suazo JA, Demestre Guasch X, Garcia Reymundo M, Ginovart Galiana G, Gimenez A, Calvo Aguilar MJ, Trincado Aguinagalde MJ, Fernandez Colomer B. Comparison of perinatal data between a cohort of Spanish late preterm babies and another of term newborns. J Perinatal Med. 2015;43(SUPPL. 1).

52. Iglesias S, Bott N, Ellehoj E, Yee J, Jennissen B, Bunnah T, Schopflocher D. Outcomes of maternity care services in Alberta, 1999 and 2000: a population-based analysis. JOGC. 2005;27(9):855-63.

53. Karalis E, Gissler M, Tapper AM, Ulander VM. Influence of time of delivery on risk of adverse neonatal outcome in different size of delivery units: a retrospective cohort study in Finland. J Maternal-Fetal Neonatal Med. 2019;32(10):1696-702.

54. Koch R, Gmyrek D, Vogtmann C. Risk adjusted assessment of quality of perinatal centers - results of perinatal/neonatal quality surveillance in Saxonia. Risikoadjustierte Qualitatsbeurteilung in Perinatalzentren ausgehend von der Perinatal- und Neonatalerhebung in Sachsen. 2005;209(6):210-8.

55. Kozhimannil KB, Interrante JD, Henning-Smith C, Admon LK. Rural-Urban Differences In Severe Maternal Morbidity And Mortality In The US, 2007-15. Health affairs (Project Hope). 2019;38(12):2077-85.

56. Krzyzak M, Maslach D, Piotrowska K, Charkiweicz AE, Szpak A, Karczewski J. Perinatal mortality in urban and rural areas in Poland in 2002-2012. Przegl Epidemiol. 2014;68(4):675-9.

57. Lesniczak B, Krasomski G, Rudnicka B, Piekarska E, Oszukowski P, Wozniak P. The perinatal mortality of fetuses and neonates in Poland in the years 1960-2010. Ginekologia i Poloznictwo. 2015;36(2):40-5.

58. Lorch SA, Srinivas SK, Ahlberg C, Small DS. The impact of obstetric unit closures on maternal and infant pregnancy outcomes. Health Serv Res. 2013;48(2 Pt 1):455-75.

59. Neto MT. Perinatal care in Portugal: effects of 15 years of a regionalized system. Acta Paediatrica. 2006;95(11):1349-52.

60. Parazzini F, Cipriani S, Bulfoni G, Bulfoni C, Bellu R, Zanini R, Mosca F. Mode of delivery and level of neonatal care in Lombardy: a descriptive analysis according to volume of care. Ital J Pediatr. 2015;41:24.

61. Payne JC, Campbell MK, DaSilva O, Koval J. Perinatal mortality in term and preterm twin and singleton births. Twin Res. 2002;5(4):260-4. 
62. Poeran J, Borsboom GJJM, de Graaf JP, Birnie E, Steegers EAP, Mackenbach JP, Bonsel GJ. Does centralisation of acute obstetric care reduce intrapartum and first-week mortality? An empirical study of over 1 million births in the Netherlands. Health Policy. 2014;117(1):28-38.

63. Ravelli ACJ, Tromp M, van Huis M, Steegers EAP, Tamminga P, Eskes M, Bonsel GJ. Decreasing perinatal mortality in The Netherlands, 2000-2006: a record linkage study. J Epidemiol Community Health. 2009;63(9):761-5.

64. Reid LD, Creanga AA. Severe maternal morbidity and related hospital quality measures in Maryland. J Perinatol. 2018;38(8):997-1008.

65. Shuvalova MP, Yarotskaya EL, Pismenskaya TV, Dolgushina NV, Baibarina EN, Sukhikh GT. Maternity Care in Russia: Issues, Achievements, and Potential. JOGC. 2015;37(10):865-71.

66. Treurniet HF, Looman CW, van der Maas PJ, Mackenbach JP. Regional trend variations in infant mortality due to perinatal conditions in the Netherlands. Eur J Obstet Gynecol Reprod Biol. 2000;91(1):43-9.

67. Harvey SM, Oakley LP, Yoon J, Luck J. Coordinated Care Organizations: Neonatal and Infant Outcomes in Oregon. Med Care Res Rev. 2019;76(5):627-42.

68. Merlo J, Gerdtham U-G, Eckerlund I, Hakansson S, Otterblad-Olausson P, Pakkanen M, Lindqvist P-G. Hospital level of care and neonatal mortality in low- and high-risk deliveries: reassessing the question in Sweden by multilevel analysis. Med Care. 2005;43(11):1092-100.

69. Serenius F, Winbo I, Dahiquist G, Kallen B. Cause-specific stillbirth and neonatal death in Sweden: a catchment area-based analysis. Acta Paediatrica. 2001;90(9):1054-61.

70. de Graaf JP, Ravelli AC, Visser GH, Hukkelhoven C, Tong WH, Bonsel GJ, Steegers EA. Increased adverse perinatal outcome of hospital delivery at night. BJOG. 2010;117(9):1098-107.

71. Barbaro RP, Odetola FO, Kidwell KM, Paden ML, Bartlett RH, Davis MM, Annich GM. Association of hospital-level volume of extracorporeal membrane oxygenation cases and mortality. Analysis of the extracorporeal life support organization registry. Am J Respir Crit Care Med. 2015;191(8):894-901.

72. Pasquali SK, Li JS, Burstein DS, Sheng S, O'Brien SM, Jacobs ML, Jaquiss RD, Peterson ED, Gaynor JW, Jacobs JP. Association of center volume with mortality and complications in pediatric heart surgery. Pediatrics. 2012;129(2):e370-376.

73. Powell AE, Davies HTO, Thomson RG. Using routine comparative data to assess the quality of health care: understanding and avoiding common pitfalls. Qual Saf Health Care. 2003;12(2):122.

74. Shah PS, Mirea L, Ng E, Solimano A, Lee SK. Association of unit size, resource utilization and occupancy with outcomes of preterm infants. J Perinatol. 2015;35(7):522-9.

75. Lake ET, Hallowell SG, Kutney-Lee A, Hatfield LA, Del Guidice M, Boxer BA, Ellis LN, Verica L, Aiken LH. Higher Quality of Care and Patient Safety
Associated With Better NICU Work Environments. J Nurs Care Qual. 2016;31(1):24-32

76. Lake ET, Staiger D, Horbar J, Cheung R, Kenny MJ, Patrick T, Rogowski JA. Association between hospital recognition for nursing excellence and outcomes of very low-birth-weight infants. JAMA. 2012;307(16):1709-16.

77. Kozhimannil KB, Hung P, Henning-Smith C, Casey MM, Prasad S. Association Between Loss of Hospital-Based Obstetric Services and Birth Outcomes in Rural Counties in the United States. JAMA 2018;319(12):1239-47.

78. Grzybowski S, Stoll K, Kornelsen J. Distance matters: a population based study examining access to maternity services for rural women. BMC Health Serv Res. 2011;11:147.

79. Kornelsen J, Stoll K, Grzybowski S. Stress and anxiety associated with lack of access to maternity services for rural parturient women. Aust J Rural Health. 2011;19(1):9-14.

80. McAteer JP, LaRiviere CA, Drugas GT, Abdullah F, Oldham KT, Goldin AB. Influence of surgeon experience, hospital volume, and specialty designation on outcomes in pediatric surgery: a systematic review. JAMA Pediatr. 2013;167(5):468-75

81. Riley RD, Lambert PC, Abo-Zaid G. Meta-analysis of individual participant data: rationale, conduct, and reporting. BMJ. 2010;340:C221.

82. Riley RD, Lambert PC, Staessen JA, Wang J, Gueyffier F, Thijs L, Boutitie F. Meta-analysis of continuous outcomes combining individual patient data and aggregate data. Stat Med. 2008;27(11):1870-93.

83. Shea BJ, Reeves BC, Wells G, Thuku M, Hamel C, Moran J, Moher D, Tugwell P, Welch V, Kristjansson E, et al. AMSTAR 2: a critical appraisal tool for systematic reviews that include randomised or non-randomised studies of healthcare interventions, or both. BMJ. 2017;358:j4008.

84. McPherson K. International differences in medical care practices. Health Care Financ Rev. 1989;Spec No(Suppl):9-20.

85. Walt G, Shiffman J, Schneider H, Murray SF, Brugha R, Gilson L. "Doing" health policy analysis: methodological and conceptual reflections and challenges. Health Policy Plan. 2008;23(5):308-17.

86. Hug L, Alexander M, You D, Alkema L. National, regional, and global levels and trends in neonatal mortality between 1990 and 2017, with scenariobased projections to 2030: a systematic analysis. Lancet Glob Health. 2019;7(6):e710-20.

\section{Publisher's Note}

Springer Nature remains neutral with regard to jurisdictional claims in published maps and institutional affiliations.
Ready to submit your research? Choose BMC and benefit from:

- fast, convenient online submission

- thorough peer review by experienced researchers in your field

- rapid publication on acceptance

- support for research data, including large and complex data types

- gold Open Access which fosters wider collaboration and increased citations

- maximum visibility for your research: over $100 \mathrm{M}$ website views per year

At BMC, research is always in progress.

Learn more biomedcentral.com/submissions 